\title{
Chapter 4 \\ What Responsible Businesses Can Learn from Social Innovation
}

\author{
Josephina Antoniou
}

\begin{abstract}
This chapter presents initiatives and success stories from the realm of social innovation with the aim of identifying elements of Responsible Innovation (RI) and their significance. The motivation behind selecting social innovation to highlight the positive impact of RI practices is twofold. Focusing on social innovation provides, primarily, an opportunity to investigate the business perspective, by looking into cases where businesses have reconnected with the community through shifting their focus towards serving society, as a means to become more successful. Often this leads to immediate benefits for the business but also sets the framework for a long-term strategy that goes beyond well-known corporate social innovation activities, to encompass further activities that potentially initiate and support both social and environmental change. In addition, the focus on social innovation allows a better view of the community perspective, by considering the public as important business stakeholders, i.e. consumers and customers. As such, the public increasingly demands that business practices are handled in a more ethical way. As societies become more vulnerable due to economic instabilities, resource crises and political changes, the public demands adoption of new ways of thinking, and it is often implied that the road to a successful economic, and often cultural, transformation needs to go through social innovation. Undoubtedly, the goal of social innovation is to provide socially beneficial solutions that drive economic growth, but the task is not an easy one. Therefore, RI is essential for driving society forward, especially when it comes to the key aspects of employment, education and social inclusion.
\end{abstract}

Keywords Responsible innovation $\cdot$ Public good $\cdot$ Social innovation $\cdot$ Economic growth

\footnotetext{
J. Antoniou ( $\square)$

University of Central Lancashire, School of Sciences, Pyla, Cyprus

e-mail: JAntoniou@uclan.ac.uk
} 


\subsection{Introduction}

This chapter aims to identify elements of Responsible Innovation (RI) in various initiatives and success stories from the realm of social innovation. The featured initiatives show that RI elements are significant in social innovation, especially in terms of public good.

The motivation behind selecting social innovation to highlight the positive impact of RI practices is twofold. Focusing on social innovation gives us an opportunity to investigate the business perspective, by looking into cases where businesses have reconnected with the community through shifting their focus towards serving society, as a means to become more prosperous and successful. Often this leads to immediate benefits for the business but also sets the framework for a longterm strategy that encompasses more than just the well-known corporate social innovation activities, but includes further activities that could potentially initiate and support both social and environmental change. We also focus on social innovation to open up the community perspective, by viewing the public as a group of important business stakeholders, i.e. consumers and customers. As such, the public increasingly demands that business practices are handled in a more ethical way. In fact, as societies are becoming more vulnerable due to economic instabilities, resources crises and political changes, the public demands adoption of new ways of thinking, and it is often implied that the road to a successful economic, and often cultural, transformation lies through social innovation.

The selected initiatives from business included in this chapter demonstrate how social innovation with RI elements have resulted in increased business productivity, lower business costs, and several other benefits. Section 4.2 presents the idea of innovation management through the development of new social incubators for socially innovative SMEs in Europe. Section 4.3 identifies RI elements in social innovation achieved through citizen-generated initiatives, while Sect. 4.4 follows social innovation and consequently RI aspects through addressing gender challenges. Section 4.5 offers the chapter conclusions.

\subsubsection{Defining social innovation}

Defining social innovation is challenging, especially within the scope of business growth. Looking at business growth through the lens of social innovation is often easier, especially in emerging markets "characterised by a rapidly expanding middle class and growing consumer spending" (Chakravorti and Siesfeld 2015). In such markets social innovation which stems from business includes activities that are community-engaging and inclusive, as well as activities that support business sustainability and further growth. In fact, social innovation aims at implementing effective solutions to important social, community and environmental issues, which are, 
more often than not, driven by local and global businesses in an effort to motivate societal growth and support business sustainability.

\subsubsection{Social Innovation and Economic Growth}

Undoubtedly, the goal of social innovation is to provide socially beneficial solutions that drive economic growth, but the task is not an easy one. RI as an outcome seeks to generate the right 'end points', which benefit people, planet, and profit (Sutcliffe 2011). Social innovation across Europe is such an 'end point', according to the Europe 2020 strategy, so it would seem necessary to identify the starting point in the values and rights of citizens of the European Society. To support these values and rights, the growth strategy for Europe 2020, articulates a vision for a smart, sustainable and inclusive economy, delivering high levels of employment, productivity and social cohesion (Sutcliffe 2011).

Innovation is essential for driving society forward, especially when it comes to the key aspects of employment, education and social inclusion. In order to move towards such benefits, it is important to involve the public and civil society stakeholders in the RI process. Thus, these stakeholders can become co-creators in the social innovation process. Given that RI aims to support a refinement of the roles and responsibilities of stakeholders with regards to innovation in business, specific elements of RI can strengthen social innovation.

In cases where the avenue for social innovation comes through business and, in particular, Small to Medium Enterprises (SMEs), then such innovation becomes more challenging. Overall, innovation is paramount to the survival and growth of any business (Mwangi and Namusonge 2014); however, SMEs are not always able to support RI fully. The incorporating of RI processes should be approached differently in SMEs to large organizations (which often support dedicated Corporate Social Responsibility (CSR) departments), because it may be the case that SMEs are unable or unwilling to consider the trade-off between immediate profit, and RI support mechanisms for non-immediate value in terms of profit.

RI elements in industry are usually aligned to a company's social innovation initiatives, even though RI discourse has "predominantly been designed to be applied to publicly funded research and innovation activities" (Soraker and Brey 2014). Even so, these activities are often linked with an intended social impact. To achieve the same social impact from privately funded initiatives, i.e. SMEs and larger organizations, this must be included in the planning stage for implementing social innovation initiatives, considering all stakeholders, in order to involve a range of expertise and perspectives (Stilgoe et al. 2013). Therefore, it becomes significant to focus on core aspects of RI and explore the applicability of these aspects in industry.

Consequently, this chapter identifies social innovation examples that demonstrate elements of RI and it highlights these elements, showing how they are aligned with industrial targets, and that RI implementation can often add benefits that can 
inform the business case. In the following sub-sections, a set of initiatives is presented and RI aspects are highlighted in corresponding social innovation success stories, to demonstrate the beneficial use of the particular RI aspects in industry, and to SMEs. The selected RI aspects include open innovation and open access and their contribution to business sustainability, environmental considerations, and ethical considerations, as well as policies, standards and codes of conduct, gender and diversity issues, and workplace equality.

\subsection{Social Innovation Through Innovation Management and Incubation Initiatives}

This section addresses social innovation through incubation, a popular mode of managing innovation and simultaneously promoting social impact. Innovation management is the management of such activities as idea generation, and the development of technologies, products or processes. Consequently, there is benefit in incorporating contributions from relevant experts, such as sociologists, psychologists, statisticians, engineers, etc. Innovation can be understood as novelty brought to (economic) use, so Research and Development (R\&D) management can also be innovative. This has often been combined with CSR initiatives, and is now included through RI aspects in related industrial initiatives. Overall, it is important to understand that RI "is still very much a work in progress" (Soraker and Brey 2014). However, there is a need to move away from theoretical conceptualisation and consequent ambiguity, and offer more concrete translation of the RI concept into business practice (Owen et al. 2012).

$\mathrm{RI}$ can be a tool that provides a business with "guidance on how to move from an abstract concept to a more concrete approach" (Davalli 2017), so that entrepreneurs and business decision-makers can identify and take advantage of the new potential that RI can offer. This potential may vary between SMEs in different sectors, which can be explored through the exploration of specific challenging business sectors, e.g. where technology is key, such as biomedicine, nanotechnology, and cyber security. However, SMEs practicing in different sectors may also share common horizontal aspects of RI, which is particularly significant for SME innovation management.

For example, companies within the nanotechnology sector are expected to promote and support a high level of innovation that relates to society, as it is a sector "impacting modern social life and economies" (Galatsis et al. 2015). Recently the sector has been transformed by information technology. This transformation was caused by a rapidly growing technological sector, and has resulted in challenging social issues that need to be addressed, such as job losses, or gender equality and diversity in technical sectors. There is an imminent need for responsible practices to address these social issues, in addition to many others that fall under the umbrella 
of responsibility, such as environmental issues, or new policies, which are discussed in detail in subsequent sections.

Further examples of such aspects can be observed in the sectors of cyber security and biomedicine. Specifically, social innovation is addressed within the context of cyber security, where it is often related to the protection of social infrastructure from security threats. These new technological threats often relate to the increasingly popular Internet of Things concept, where devices and people are all connected, and are supported by the same networking infrastructure, with cyber security companies providing tools to protect this all-accessible infrastructure against non-responsibly acting malicious attackers (Miyao 2016). The cyber security effort needs to consider both the technological and organizational levels, and a wider implementation of RI can act as an ally in this effort. In addition, innovation and growth has been promoted within the area of biomedicine, which relates to "the changing relationship between the private and public sector in the use of human genomics and personal medical information" (Martin and Hollin 2014). The relationship is transforming into a collaborative one, offering a better foundation for responsible practices in the private sector that will be encouraged by the public sector. Martin and Hollin (2014) recognize that the sector is moving in this direction; "throughout the 2000s a series of UK and EU public policy initiatives were taken to promote innovation and growth of the [...] commercial development of biotechnology in particular".

According to Mwangi and Namusonge (2014), and based on Annual Reports from the United Nations Industrial Development Organization (UNIDO), SMEs constitute more than $90 \%$ of enterprises worldwide; therefore, it is significant for SMEs to have the opportunity to target cross-sectoral aspects and opportunities for added value. Overall, cross-sectoral aspects of innovation and responsibility have been targeted by CSR, a concept quite closely related to RI. However, the concept of RI is concerned with carrying out research and innovation responsibly, with consideration for the potential impacts for society; CSR is a more industry-driven concept, incorporating responsible strategies such as community philanthropies (Soraker et al. 2017), in order to strengthen businesses' profile, or corporations' roles in the market.

It is important to note that studies have shown CSR is associated mostly with large companies rather than SMEs. Larger companies are more concerned with their public profile because they attract more media attention and they are "particularly concerned to protect and enhance their reputation with the broader public as well as key stakeholders" (Smith 2013). Nevertheless, responsibility should concern companies of all sizes, especially when SMEs have obvious advantages, such as commitment by the management, personal relationships among employees, and less-obvious advantages such as comparatively fewer resources, all of which can help elevate business profitability potential by engaging with RI (Smith 2013).

The initiatives discussed in this section aim to demonstrate how RI aspects can be highlighted within social innovation case studies that have resulted in the following benefits: support structures for social innovation (e.g. incubators and additional job opportunities), increased business productivity and lower costs for the 
companies. In fact, incubation for social innovation startups can foster and support companies that are committed to innovation management structures, and consequently the adoption of several RI aspects.

The selected social innovation success stories begin with two European projects (BENISI and TRANSITION), which developed new social incubators for socially innovative SMEs. Both BENISI \& TRANSITION are socially innovative projects launched by the European Commission that are mandated to help social entrepreneurship and innovation in Europe in local, regional and international contexts.

BENISI $^{1}$ is a project for building a European network of incubators for social innovation, where local social enterprises are supported in scaling up and growing beyond their locality. In addition to supporting the scaling up of social enterprises across Europe, TRANSITION ${ }^{2}$ also provides learning output on which scaling methodologies are most effective in a given region. Statistics from the EBN Annual Observatory and Impact Hub Network on the success stories of BENISI and TRANSITION show the impact on social innovation across Europe. Specifically, incubated companies (i.e. socially innovative SMEs) show a high $90 \%$ survival rate after 3-5 years, post-incubation phase. For example in 2014, 3000 SMEs were developed in 150 incubators and innovation centres, creating 13,000 jobs with an average contribution by the SMEs of 8000 Euros per job (Davalli et al. 2016).

Another interesting initiative comes from Nigeria, although it was implemented in a very different setting from European SMEs. The Small and Medium scale industries Equity Investment Scheme (SMEIES) is an initiative of the bankers' committee in Nigeria. The commercial and merchant banks have agreed to set aside $10 \%$ annually of their profits before tax as their contribution to the development of SMEs, encouraging meaningful employment generation and the development of indigenous technology, (Mohammed and Abimiku 2015) to achieve significant social impact in terms of employment opportunities. These new financing approaches recognized the inherent weakness of SMEs in terms of resources, and the need to design finance schemes and products that are unique to them. To achieve the required employment generation through development of technology, innovation management, and more specifically responsible innovation, are inherently adopted by the specific companies.

Similar features and needs are observed to different degrees in SMEs globally. There are lessons to be extracted here, since one of the demotivating factors for SMEs when implementing RI is usually the lack of resources (Soraker and Brey, 2014). External support through incubation and further innovation management support could be sufficient motivation to engage SMEs with the RI implementation process, but external support need not always be financial; it can exist in the form of support for training (European Commission 2009), clustering (Organisation for Economic Co-operation and Development 2000), etc.

A third case study of social innovation through an incubation initiative is the case of Nesta in India; Nesta is an innovation foundation that looks for ways to bring

\footnotetext{
${ }^{1}$ www.benisi.eu

${ }^{2}$ www.transitionproject.eu
} 
great ideas to life. To achieve this, Nesta invests in research and innovation, and manages this process by considering the difficulties of providing social impact in a challenging environment, since India is the home of a third of the world's poor (Gabriel et al. 2016). Nesta has succeeded in addressing this challenge by working with incubators to establish a more sophisticated set of impact and success metrics for incubation in low-income states in India. The success of Nesta comes from the fact that innovation management and specific aspects of RI (as per the previously presented definitions) are incorporated in the strategy to support business growth in the challenging environment, rather than primarily to achieve social impact, although it eventually does. According to Srikumar Misra, the Founder and CEO of Nesta, "We don't classify ourselves as a social enterprise... Our philosophy is about 'conscious capitalism'... Impact is built into the way we structured the business" (Gabriel et al. 2016).

Innovation management, and in particular corporate innovation management, as is the case when considering the implementation of RI aspects, has been addressed within many corporate strategies to provide a solution for the challenge of any corporate business; that the workforce is eventually trapped within a certain routine without ever thinking outside the box (Mitra 2016). Corporate innovation management aims to support ways of encouraging creativity and innovation. Sramana Mitra (2016), the founder of One Million by One Million, a virtual incubator helping one million entrepreneurs, globally, reach one million dollars, has repeatedly emphasized the importance of corporate innovation management and how the workforce should be trained to identify and validate innovation opportunities.

$\mathrm{RI}$ is closely linked to this concept, as it is a process, "by which societal actors and innovators become mutually responsive to each other with a view to the acceptability, sustainability and societal desirability of the innovation process" (Von Schomberg 2012). Implementing an RI framework within a company, whether this is a large corporation or an SME, ensures the desired corporate innovation management that will provide a platform for evolution and creativity through innovation; ensuring that it is explored responsibly, i.e. ethically and transparently in sustainable, highly reputable ways.

\subsection{Social Innovation Through Citizen-Motivated Initiatives}

Often, citizens are eager to participate in the social innovation process, as active stakeholders. Evolving communication technology is shifting the dynamics of the provider-customer relationship, offering the opportunity to customers, i.e. citizens themselves, to support (or not) a particular business and its practices. Companies can use open innovation tools to generate new ideas and invite the world to solve problems together, but also, consumers can act around an issue and pressure companies to change their behaviour.

Several examples of the use of social media in relation to responsible practice, which can strengthen or weaken a company's reputation, and consequently the 
potential for its future business sustainability, are presented in this chapter. One of them is the case of Crayola, which was featured in social media in 2013, as a company needing to enhance its recycling practices for marker pens. This campaign was started by an elementary school's class video, which got the attention of the company. Crayola responded by committing to helping reduce waste and pollution (Savedge 2013).

Such citizen-motivated initiatives have often developed from a local effort to a global campaign. Although there is a risk for companies when engaging in a dialogue with their customers, there are also a number of benefits; the main benefit being that by engaging with open communication tools, e.g. social media, an enhanced reputation of the business with its customer base may be achieved. For instance, according to The Guardian (2014), Unilever, which is a leader in CSR, has used an online open forum to hold a discussion for 2 years on sustainability issues, including the impact on the environment from the use of its products, and has posted a list of "challenges and wants" to request ideas for solving big issues, receiving more than one thousand ideas from the public in return. ${ }^{3}$ Also, InnoCentive, EMC and $\mathrm{EDF}^{4}$ ran its first Eco-Challenge activity in 2012 through similar platforms, seeking solutions for tracking shipments of used electronic components and subsystems to ensure that they are disposed of in a responsible manner. Another notable open innovation model included Heineken's $\$ 10,000$ sustainable packaging contest ${ }^{5}$ in 2012, which asked the public to propose ideas for sustainable beer packaging, and yielded numerous quality ideas from designers around the world based mainly on innovativeness and feasibility.

Consumers can act around a green issue and pressure companies to change their behaviour. Some notable campaigns have challenged specific companies, such as in the case of Crayola mentioned above. This provides an opportunity for companies to take action in order to rectify the relationship with their customers as well as to reinforce a responsible reputation once the social media movements break out. Other than Crayola, companies affected by such campaigns include Universal Pictures, and Dunkin' Donuts.

Universal Pictures was singled out by the public on social media for adding environmental education to The Lorax movie, especially the movie website. The campaign was started by students and was completed successfully in 2012. Dunkin' Donuts was asked by the public to replace its styrofoam cups, with a more environmentally-friendly alternative, by starting a petition that was eventually signed by more than three hundred thousand people, which gained recognition in national USA news. The company committed to the replace all styrofoam cups by 2020 .

\footnotetext{
${ }^{3}$ https://www.greenbiz.com/blog/2012/06/07/how-unilever-crowdsourced-creativity-meetsustainability-goals

${ }^{4} \mathrm{https}$ ///www.innocentive.com/emc-edf-and-innocentive-launch-new-eco-challengefor-crowdsourced-solutions-to-key-e-waste-issue/

${ }^{5}$ http://www.sustainablebrands.com/news_and_views/articles/heineken-launches-openinnovation-challenge
} 


\subsection{Social Innovation Through Open Access}

A concept related to open communication is open access. Open access is a research principle which promotes openness, transparency, and integrity. It aims to allow access to knowledge for all through open access to peer-reviewed literature, enabling the participation of society and improving research collaborations. This research and innovation principle appears at first glance to be contradictory to the private nature of enterprises participating in a competitive market, where it is not expected to share and collaborate. The goal is to find a common ground between the two worlds, in a way that will be beneficial for companies to adopt the principle of openness, without compromising their competitive edge in the market.

Where companies receive funding, e.g. through the European Commission's Horizon 2020 programme, then they must participate in open access publications. Moreover, initiatives such as Science 2.0 (trademark by ION Publications LLC), as well as concepts such as Open Science and Open Data, and Business Communication 2.0 that complement Open Access and motivate this paradigm further. In the following paragraphs, the aforementioned concepts will be further elaborated and contextualized.

The definition for the concept of Open Data is taken from the Open Data Handbook promoted by Open Knowledge International, a global non-profit organization focused on realizing open data's value to society. According to the Open Data Handbook, which is a set of guides, case studies and resources mainly for government and civil society on why and how to use open data, data must be both technically open and legally open. More importantly, the question of how Open Data is useful to SMEs is addressed in Open Data: A twenty-first century asset for small and medium-sized enterprises (Verhulst and Caplan 2015). The report presents 354 case studies of companies (SMEs and start-ups) that are using open data and how this can contribute to each company's economic growth. The report emphasizes that the open and shared data trend has "the power to fuel economic growth, job creation and new business opportunities".

The concept of Open Science promote scholarly sharing assisted by technology, especially new technologies like Web 2.0. The Science 2.0 initiative is based on the Open Science concept. Examples may include scientists using collaborative technology to share ideas, data or findings. Collaborative web technology provides several tools to achieve such collaborations, for instance, wikis, blogs and video journals (Waldrop 2008). Overall, open innovation achieved through Science 2.0 and Open Science concepts and tools, and further supported by Web 2.0 technologies, offer new opportunities for collaboration, research and education through harnessing collective intelligence (Tacke 2010). This can be a powerful asset for SMEs, which are usually under-resourced in terms of a wide variety of scientific expertise. This is especially applicable in highly technical sectors and corresponding SMEs.

The concept of Business Communication 2.0 addresses how the process of communication in business has been affected by, and needs to be further adjusted to certain technology advancements that are rapidly becoming the new communica- 
tion norms. Social media and social networking technologies are examples of such new communication norms, where the underlying principles of the new communication pathways focus on the lack of geographical boundaries, and a sense of community, openness, and transparency. The use of new communication and networking paradigms has already begun to affect how business is done. Given the continuous evolution of virtualization, contextualization, and novel ways of data mining in the information world, it should be expected that this information-sharing trend will continue to penetrate the business communication world, through the use of more media reaching more stakeholders.

\subsection{Social Innovation Through Addressing Gender Challenges}

RI involves gender equality as one core societal aspect, which also intersects with other dimensions of RI (Lindberg and Schiffbänker 2013). Examples of social inclusion tackle aspects of gender and diversity, specifically aimed towards workplace equality. Gender issues and workplace equality are addressed in an attempt to drive teams and organisations towards their full potential, especially in sectors where the imbalance and lack of diversity are more broadly evident, such as technical sectors. Overall, there have been many initiatives to overcome this lack of diversity in research and technology, and the effort is ongoing with several European projects (FP7, H2020) currently addressing these issues (EGERA, ${ }^{6}$ FESTA, ${ }^{7}$ GARCIA, ${ }^{8}$ GENERA $^{9}$ ).

This section examines gender aspects in social innovation examples as these are related to RI. Specifically it examines the current under-representation of women in research and innovation, as well as the benefits of moving towards workplace equality and how this can be applicable for SMEs, as it is especially difficult to promote both CSR and RI initiatives in SMEs because of their size, compared to larger corporations. It is important to state here that for RI, "inclusion of equality issues should not be limited on addressing gender" (Soraker et al. 2017). In addition, other diversity categories such as age, ethnicity or disability may be equally important factors for SMEs for equality reasons, but also for the quality of their research and innovation. Therefore, although the Section mostly focuses on gender aspects, SMEs as well as larger corporations should also look to issues such as age(ing), migration, ethnicity, religion, disabilities, and sexual orientation, which are part of the European non-discrimination and equality mainstreaming policy (European Commission 2012).

Thus, gender is for example an issue in open innovation, addressing the question of 'Who is participating in research?'; in ethics, addressing the question of 'How is

\footnotetext{
${ }^{6}$ http://www.egera.eu/

${ }^{7}$ http://www.festa-europa.eu/

${ }^{8}$ http://garciaproject.eu/

${ }^{9}$ http://genera-project.com/
} 
the risk of discrimination tackled?'; and in policy, addressing the question of 'Whether equality standards are implemented'.

World Wide Worx (2014) has published articles stating that "women are key to SME success". There has been an increase in female entrepreneurship since 2002 but especially since 2009 (VanderBrug 2013), but, having emphasized the importance of innovation for SMEs, there has been a lack of women in the research and innovation process (Busolt and Kugele 2009), with women forming only $28 \%$ of the world's researchers (UNESCO 2015). According to ITC News (2016), with statistics generated from approximately 20 countries around the world, close to $40 \%$ of all SMEs are owned by women. In addition, recent trends have shifted attention towards cultivating gender-friendly workplace cultures.

One of the most important initiatives addressing gender and equality issues in companies, and especially SMEs, is the United Nations 2030 Development Agenda, which has been adopted by 193 countries and focuses on sustainable development goals, especially on the "transformation of discriminatory norms and gender stereotypes". Among the goals of the agenda to be achieved by 2030 is the following:

Ensure that all men and women, in particular the poor and the vulnerable, have the equal right to economic resources, as well as basic services, ownership and control over land and other forms of property. (United Nations 2015)

This includes policies aiming to encourage an increase of women in SME participation in international trade. The UN 2030 Development Agenda discusses the need for enhancing women's economic education and training to support their equal rights and responsibilities, giving special attention to promoting the economic role of women the economy in general, and particularly in SMEs.

A 2015 article by the International Labour Organization (ILO), highlights the contributions of the SCORE project in contributing to gender equality in SMEs in developing countries. The article emphasizes that the "ILO has long supported the fight for equality in the world of work, through the development and promotion of labour standards, gender focused campaigns - such as the Women at Work Century Initiative" and that it is important how the SCORE project raises "awareness of gender issues among managers and employees" through training and support visits to SMEs.

Another successful initiative comes from the European Small Business Portal, which features success stories from SMEs across Europe. The stories are featured on the European Commission website and include an initiative from a Slovakian SME. Regionfemme is run by entrepreneur Luica Haquel, which provides consulting and training for women to start up their own businesses. By 2014, only 5 years after funding was received by the EU to launch Regionfemme, and 2 years after the participants concluded their trainings, Regionfemme had already made a difference, with 56 out of 107 participants opening their own businesses, thus increasing women entrepreneurs in Europe.

Additional initiatives include: UKRD Group, Gendered Innovations, Yellow Window, and GenPORT. UKRD Group is a multimedia company in the UK; diversity management is central to the company's human resource strategic goals, which include the development of an inclusive and integrated workforce. Gendered 
Innovations is an ongoing website project which collects and documents case studies of research and innovation which highlights the relevance of gender issues. Yellow Window provides a toolkit (process model and checklist) for considering gender during the whole research and innovation process. GenPORT represents a community of practice concerning gender issues in science, technology and innovation.

The benefits from such initiatives are twofold, i.e. both for the business and for society overall. Specifically, in the above case studies, it has been observed that the adoption of gender, and overall workforce equality practices, has resulted in increased business opportunities, enhanced workforce morale, more opportunities for training and for employment, and overall improvement in productivity.

\subsection{Chapter Conclusions}

Overall, this chapter identifies and discusses social innovation initiatives and success stories highlighting elements of RI implementation in companies across Europe, and especially SMEs. The chapter also addresses ways of creating a conducive environment for innovation, keeping in mind that social innovation is an emerging practice and discipline for NGOs (Bond 2016). Moreover, investigating the RI core aspects, it is evident that they cannot be useful in all possible corporate scenarios in the same way, especially where SMEs are concerned. According to the literature, incentives for an SME should directly reflect profit, or profit potential, and thus Soraker et al. (2017) emphasize the need to demonstrate that RI can result in:

strengthening links with customers and end-users, enhancing the company reputation, decreasing business risks and unintended consequences, strengthening public trust in the safety of products, adopting an environmentally friendly profile.

The chapter shows that while profit-oriented incentives are certainly viable, a business's contribution to solving societal challenges is also an overarching benefit, and businesses have engaged in several social innovation initiatives, or have structured their operations so as to result in some kind of social impact. This has been achieved in several ways, including innovation management through incubation, open communication with citizens and customers, as well as attempts to support overall workplace equality practices.

Furthermore, the chapter discusses aspects of RI that are aligned with the above targeted social innovation case studies, where benefits have been evident and tackled by relevant research and discourse. Each section discusses the importance of the specific aspect and provides a list of initiatives and success stories to demonstrate the beneficial use of the particular aspect in industry, and more specifically SMEs, where the most challenges exist in implementing these aspects.

The selected cases included in this chapter demonstrate how social innovation with RI elements can result in increased business productivity, lower business costs, 
and several other benefits. Such cases include innovation management through the development of new social incubators for socially innovative SMEs in Europe, as well as social innovation achieved through citizen-generated initiatives. Finally, the chapter does not ignore the importance of addressing gender aspects in business through examples that demonstrate how the gender aspect can promote RI in business. It is significant to highlight through these cases that RI is essential for driving society forward, especially when it comes to the key aspects of employment, education and social inclusion.

\section{References}

Bond. (2016). An introduction to Social Innovation for NGOs, Licensed under a Creative Commons Attribution-Non Commercial 4.0 International License, London, UK.

Busolt, U., \& Kugele, K. (2009). The gender innovation and research productivity gap in Europe. International Journal of Innovation and Sustainable Development, 4(2-3), 109-122.

Chakravorti, B., \& Siesfeld, T. (2015). Business growth for good: Why context matters. Stanford Social Innovation Review, (Jul. 15, 2015).

Davalli, C. (2017). All scale innovation, RRI tools blog. Posted: January 2017. https://blog.rritools.eu/-/all-scale-innovation

Davalli, C., et. al., eds. (2016). Scaling Social Innovation. BENISI - TRANSITION: experiences and first success stories of the two European networks of incubators for social innovation. Joint Report of BENISI and TRANSITION projects, DG Research and Innovation, FP7-CDRP-2013-INCUBATORS.

European Commission. (2009). Guide for Training in SMEs, Directorate-General for Employment, Social Affairs and Equal Opportunities, Unit F.3.

European Commission. (2012). Responsible research and innovation: Europe's ability to respond to societal challenges. Research and Innovation Policy. https://doi.org/10.2777/11739.

Galatsis, et. al. (2015). Nanoelectronics research gaps and recommendations, IEEE Society and Technology Magazine, June 2015, pp. 21-30.

ITC News. (2016 October 16). How does gender affect the participation of SMEs in International Trade? Speech by ITC Executive Director Arancha Gonzalez, Canada.

Lindberg, M., \& Schiffbänker, H. (2013). Entry on gender and innovation. In E. G. Carayannis (Ed.), Encyclopedia of creativity, invention, innovation and entrepreneurship. New York: Springer.

Martin, P., \& Hollin, G. (2014). A new model of innovation in biomedicine? http://nuffieldbioethics.org/wp-content/uploads/A-New-Model-of-Innovation_web.pdf

Mitra, S. (2016). Corporate innovation management: Lessons learned, one million by one million blog. Posted: July 2016, Accessed: December 2016.

Miyao, T. (2016). Protecting social infrastructure from creeping threats - robust security against attack is not achieved in a day, Social Innovation Hub, Hitachi. http://social-innovation.hitachi/ eu/topics/security/index.html

Mohammed, A., \& Abimiku, J. (2015). Innovation among small and medium Enterprises in Nigeria. Journal of Resourcefulness and Distinction, 11, 1.

Mwangi, M. S., \& Namusonge, M. J. (2014). Influence of innovation on small and medium Enterprise (SME) growth - A case of garment manufacturing Industries in Nakuru County. International Journal of Innovation Education and Research, 2(5), 31-41.

Organisation for Economic Co-operation and Development. (2000). Small and Medium-sized Enterprises: Local Strength, Global Reach, OECD Observer Policy Brief June 2000. 
Owen, R., Macnaghten, P., \& Stilgoe, J. (2012). Responsible research and innovation: From science in society to science for society, with society. Science and Public Policy, 39(6), 751-760.

Savedge, J. (2013). Kids convince Crayola to recycle markers, Mother Nature Network: Family, http://www.mnn.com/family/family-activities/blogs/kids-convince-crayola-to-recycle-markers

Smith, C. N. (2013). When it comes to CSR, size matters, INSEAD Knowledge, FORBES. http:// www.forbes.com/sites/insead/2013/08/14/when-it-comes-to-csr-size-matters/\#50c069811b6f

Soraker, J. H., \& Brey, P. A. E. (2014). Current Discourse of RRI, health, demographic change and wellbeing, Responsible Industry Deliverable D1.1, $7^{\text {th }}$ Framework Programme.

Soraker, J. H., et. al. (2017). Models of RRI in Industry, Responsible Industry Deliverable D3.3, 7th Framework Programme.

Stilgoe, J., Owen, R., \& Macnaghten, P. (2013). Developing a framework for responsible innovation. Research Policy, 42(9), 1568-1580.

Sutcliffe H. (2011). A report on responsible research \& innovation, matter. https://ec.europa.eu/ research/science-society/document_library/pdf_06/rri-report-hilary-sutcliffe_en.pdf

Tacke, O. (2010). Open Science 2.0: How Research and Education Can Benefit from Open Innovaton and Web 2.0; Advances in Intelligent and Soft Computing book series: "On Collective Intelligence", pp. 37-48.

UNESCO. (2015). Women in science: UIS fact sheet, UNESCO Institute for Statistics, November 2015, No. 34.

United Nations. (2015). Transforming our world: The 2030 agenda for sustainable development, united nations sustainable development knowledge platform, A/RES/70/1.

VanderBrug, J. (2013). The global rise of female entrepreneurs. Harvard Business Review, September 4, 2013. https://hbr.org/2013/09/global-rise-of-female-entrepreneurs. Accessed 2 May 2017.

Verhulst, S., \& Caplan, R. (2015). Open data: A twenty-first century asset for small and mediumsized enterprises, governance lab 2014, Creative Commons Attribution 4.0 International License.

Von Schomberg, R. (2012). Prospects for technology assessment in a framework of responsible research and innovation. In Technikfolgen abschätzen lehren (pp. 39-61). Springer.

Waldrop, M. (2008). Science 2.0. Scientific American, 298(5), 68-73.

World Wide Worx. (2014). Women are key to SME success. http://www.worldwideworx.com/ women/

Open Access This chapter is licensed under the terms of the Creative Commons Attribution 4.0 International License (http://creativecommons.org/licenses/by/4.0/), which permits use, sharing, adaptation, distribution and reproduction in any medium or format, as long as you give appropriate credit to the original author(s) and the source, provide a link to the Creative Commons license and indicate if changes were made.

The images or other third party material in this chapter are included in the chapter's Creative Commons license, unless indicated otherwise in a credit line to the material. If material is not included in the chapter's Creative Commons license and your intended use is not permitted by statutory regulation or exceeds the permitted use, you will need to obtain permission directly from the copyright holder.

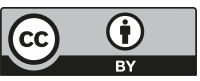

